\title{
Apøe Ciência
}

\section{EDITORIAL}

A expectativa de vida dos brasileiros aumentou, segundo o Instituto Brasileiro de Geografia e Estatística-IBGE no censo de 2010. O cenário se estende para as pessoas com deficiência e resulta da combinação de fatores como: medidas preventivas; melhoria da nutrição; avanços nas pesquisas com medicamentos, entre outros aspectos apontados pelos especialistas. Temos o que celebrar. Entretanto, questões e desafios requerem soluções nos diferentes âmbitos e setores da sociedade organizada, resumindo-se em dois aspectos: aumento da expectativa de vida saudável somada à boa qualidade de vida. O tema desta edição da Revista Apae Ciência contempla o envelhecimento da pessoa com deficiência intelectual ou múltipla, apresentando textos que remetem a importantes reflexões nos aspectos desafiadores mencionados.

O primeiro artigo, intitulado Envelhecimento e deficiência: uma dupla vulnerabilidade, é de autoria do Prof. Dr. Luiz Alberto David Araujo que, em parceria com Thaís Araujo de Oliveira Pereira de Carvalho, docente e discente, respectivamente, da PUC São Paulo, nos apresentam os vetores constitucionais de proteção aos grupos duplamente vulneráveis: idosos com deficiência. Os autores destacam, ainda, os instrumentos de defesa judicial e extrajudicial ao alcance desse público específico, ao mesmo tempo em que discutem dificuldades e obstáculos interpostos ao exercício de seus direitos.

O segundo trabalho é assinado pela Dra. Laura Maria de Figueiredo Ferreira Guilhoto, do Instituto Apae de São Paulo, e intitula-se Envelhecimento da pessoa com deficiência intelectual. Neste trabalho, a autora revisa projetos e resultados de pesquisas que tematizam o envelhecimento, tanto de pessoas da população geral, como daquelas com deficiência. Destaca o envelhecimento precoce desse público alvo, em especial com Síndrome de Down, possivelmente em decorrência de fatores biológicos ou ambientais, a exemplo da falta de políticas públicas de atendimento efetivo a esse público específico. A autora apresenta relato preliminar do Grupo de Estudo da Saúde e Envelhecimento da Pessoa com Deficiência Intelectual integrado por Organizações NãoGovernamentais na Grande São Paulo. 


\section{Apøe Ciência}

Segue-se o trabalho intitulado Envelhecimento e deficiência intelectual: o cuidador familiar como protagonista nos cuidados ao idoso, de autoria da Dra. Maria Angélica Hayar, da Pontifícia Universidade Católica de São Paulo. Apresenta revisão bibliográfica que privilegia o envelhecimento no Brasil, em especial da pessoa com deficiência intelectual, enfatizando também a figura do cuidador familiar. Destaca a dupla condição de vulnerabilidade nas quais se encontram o idoso com deficiência intelectual e seu cuidador familiar, também idoso. Pontua os desafios implicados para o Estado e as famílias, indicando uma solução importante para a questão: programas e políticas de apoio aos cuidadores familiares.

O relato de experiência apresentado pelas autoras Eliane de Fátima Trevisan Nogueira (Apae de Campinas), Ana Paula Damasceno Binoto (APAE de Campinas) e Marise Suplino (Instituto Ann Sullivan. RJ) intitula-se Envelhecimento da pessoa com deficiência intelectual na perspectiva do Currículo Funcional Natural, um modelo de atenção às pessoas com deficiência intelectual ou múltipla. Essa perspectiva de prática curricular baseia o bem-sucedido Programa Sócio-ocupacional Diversidade, criado pela APAE-Campinas em 2003 e objetiva promover saúde física, intelectual, emocional, social, condições de liberdade, dignidade, independência, autonomia, cidadania e qualidade de vida a pessoas com deficiência intelectual (DI) em processo de envelhecimento e familiares.

O trabalho de pesquisa intitulado Deficiente intelectual e família: um estudo sobre o envelhecer tem como autoras Adriana Silva Contrera Aldrigue; Fernanda de Souza e Tatiana Fernanda Pedroso dos Santos. Objetiva verificar como o envelhecimento é compreendido pelo DI e pelo seu responsável e os anseios e preocupações decorrentes. Os resultados indicaram que as pessoas deficientes tem perspectivas de futuro voltadas à constituição da própria família e acesso ao trabalho. Quanto aos responsáveis, destaca-se a preocupação com os filhos após o falecimento e o tabu frente ao desejo manifestado pelo filho para casar-se e procriar. O estudo ressalta a importância do diálogo na família. 


\section{Apøe Ciênciø}

\section{apaeciencia.org.br/revista}

Este número da Revista Apae Ciência finaliza com uma entrevista protagonizada pela admirável colaboradora e pioneira do Movimento das Apaes no Brasil Maria Amélia Vampré, mãe dedicada de um idoso com deficiência intelectual. O brilhantismo intelectual de Maria Amélia, internacionalmente reconhecido na área da deficiência e da inclusão social; sua conduta exemplar; sua bagagem cultural e contribuição para a divulgação de trabalhos e eventos enaltecem sua história e justificam as premiações e homenagens que lhe são prestadas, além do carinho que lhe dedicam os(as) companheiros(as) do Movimento Apaeano, do Brasil e de muitas partes do mundo. 